\title{
Théophile Gautier, o folhetinista ficcionista-poeta
}

\author{
Priscila Renata Gimenez ${ }^{1}$
}

\begin{abstract}
Resumo: Théophile Gautier (1811-1872) foi poeta, romancista e contista, reconhecido na plêiade da literatura do século XIX, também dedicou toda sua vida ao jornalismo. Toda sua produção para a imprensa periódica constitui relevantes documentos literários. Este estudo dedica-se a uma análise da escrita dos folhetins teatrais escritos por Gautier para o jornal parisiense La Presse na década de 1840. Tendo como base os principais estudos sobre as relações entre literatura e imprensa, além dos estudos críticos sobre o escritor-jornalista, com as análises e a explanação dos primeiros anos do autor como folhetinista teatral, visa-se demonstrar que sua crítica aos espetáculos revela conceitos artísticos e que a estética e composição de sua pena de ficcionista e poeta da era romântica, articuladas a uma escrita literário-jornalística, são inventivas e transgressoras diante do discurso típico do suporte. Na seção do folhetim destinado à revista teatral, graças à liberdade do rodapé do jornal, espaço dedicado à transposição literária da realidade, pela linguagem e pela ficção, Théophile Gautier questiona o panorama dos espetáculos bem como da realidade cotidiana, narrando e apreciando as representações e as principais de peças dramáticas e líricas de sua época.
\end{abstract}

Palavras-chave: Théophile Gautier. Folhetim teatral. La Presse. Escrita literária.

Poeta, romancista e contista, reconhecido na plêiade da literatura francesa do século XIX, a quem Baudelaire dedica suas Fleurs $d u$ Mal, Théophile Gautier foi um escritor que dedicou quase toda sua vida ao jornalismo, sobretudo à crítica de teatro, de belas artes e de literatura. Como escritor e jornalista, sua carreira se estendeu por quarenta anos de intensa atividade a partir do início dos anos de 1830. Paralelamente à sua produção ficcional e poética, Gautier trabalhou incessantemente na imprensa como crítico, diretor geral do folhetim do $L a$ Presse e redator chefe do jornal L'Artiste. Seus folhetins teatrais, ao lado das poesias, contos e romances, constituem relevantes documentos literários, além de ser uma parte essencial de sua herança ligada à história das práticas literárias e culturais intrínsecas ao jornal.

\footnotetext{
${ }^{1}$ Doutora em Letras pela UNESP/SJRP e em Literatura Francesa pela Université Paul Valéry - Montpellier III (França). Foi bolsista FAPESP, FAPESP/BEPE e beneficiada do Programa de Doutorado com Estágio no Exterior - PDEE/ CAPES. Professora do Departamento de Línguas Estrangeiras, Área de Francês, da Faculdade de Letras da Universidade Federal de Goiás desde 2016. Brasil. E-mail: priscilagimenez@ufg.br
} 
Tendo tal panorama em vista, este estudo propõe uma análise da escrita dos folhetins dramáticos produzidos por Gautier no período de fins dos anos de 1830 e década de 1840, publicados no jornal La Presse, época em que os paradigmas da imprensa moderna, que integram informação e entretenimento, já haviam se estabelecido com sucesso na produção dos periódicos franceses. ${ }^{2}$ Pretende-se demonstrar que a crítica de rodapé de Gautier, mesmo sendo produzida para o jornal e, consequentemente, para um público mais amplo, revela conceitos artísticos sólidos e intransigentes, além de estética e escrita dinâmicas e heterogêneas, as quais transitam entre princípios românticos, a concepção da arte pela arte e escrita literáriojornalística, paralelamente ao discurso objetivo e informativo, então, já próprios dos jornais diários. Neste contexto, pressupõe-se a conjectura de que Gautier se vale da liberdade do rodapé do jornal, espaço dedicado à ficção e ao olhar literário da realidade factual, para criar uma crítica aos espetáculos, articulando a atualidade teatral parisiense e a escrita literária. Isto lhe permite questionar a realidade dos espetáculos e o discurso do próprio suporte, recriando estratégias redacionais e discursivas típicas da sua pena de contista e poeta.

\section{O princípio de uma longa trajetória jornalístico-literária}

Gautier debutou na imprensa periódica em 1831 com o artigo “Arts. Buste de Victor Hugo", em Le Mercure du XIX $X^{e}$ siècle, e, em 1833, publicou sua primeira resenha sobre Salon, ${ }^{3}$ em La France Littéraire. Três anos mais tarde, em 26 de agosto de 1836, estreou no La Presse, também com uma crítica de belas-artes sobre as "Peintures de la Chambre des Députés - Salle du trone". Neste mesmo jornal, a partir de 11 de julho de 1837, foi transferido para o folhetim teatral, rubrica a que se dedicou em associação com Gerard de Nerval até fevereiro de 1838, e depois como seu único redator. ${ }^{4}$ Como folhetinista e diretor do folhetim literário, iria contribuir

\footnotetext{
${ }^{2}$ Cf. Thérenty; Vaillant, 2001 e Kalifa et al, 2011.

${ }^{3}$ No século XIX francês, o termo Salon designa os Salons de peinture et de sculpture, uma mostra das obras dos artistas da Académie des beaux-arts de Paris.

4 " $\mathrm{G}-\mathrm{G}$ " era a assinatura usada no fim dos folhetins durante o período de escrita em associação dos dois amigos e poetas. Após tal fase inicial, apesar da assinatura de "Théophile Gautier", sabe-se que o folhetinista teve a colaboração quase permanente de análises e pareceres sobre as peças feitas por amigos, principalmente músicos e compositores, que Gautier solicitava, muitas vezes, em suas correspondências. O folhetinista parafraseava os
} 
com o La Presse durante quase vinte anos, sem interrupção, ${ }^{5}$ antes de se transferir para o Moniteur Universel, em abril de 1855, também para atuar na revista dos espetáculos. É importante lembrar que Théophile Gautier, folhetinista do La Presse, foi encarregado da revista dos principais teatros dramáticos, líricos e dos concertos de Paris, diferentemente dos principais folhetinistas contemporâneos. Isto é, nesta função, ele deveria acompanhar, no mínimo, teatros da região central de Paris. Os mais importantes à época eram: Opéra, Opéra-Comique, Théâtre Italien e Conservatoire, onde se representavam espetáculos líricos e concertos; ThéâtreFrançais, Porte-Saint-Martin, Vaudeville, Gymnase, Odéon, Ambigu-Comique e Variétés, sedes do teatro dramático. No Journal des débats politiques et littéraires, outro diário prestigiado à época, por exemplo, Jules Janin, célebre crítico, se ocupou do teatro dramático durante a maior parte de sua carreira, e Hector Berlioz assinava uma crítica mais especializada, sobre óperas e concertos. Mais tarde, quando Gautier passou a participar da redação do Moniteur Universel, entre 1855 e 1864, dedicou-se exclusivamente à apreciação do teatro dramático e retomou a crítica do teatro lírico e de concertos somente em 1864, depois da morte de Fiorentino, folhetinista musical do Moniteur.

Gautier teve uma longa e ativa carreira de jornalista, que representa quase três mil textos variados publicados na imprensa, dos quais os folhetins teatrais correspondem praticamente à metade (49,4\%), segundo Martine Lavaud (2008 e 2011). ${ }^{6}$ Gautier colaborou ao longo de sua carreira no Figaro, ainda que esporadicamente, com artigos variados e também em revistas e magazines, além dos jornais em que publicava periodicamente. Dentre os magazines, o mais importante foi o Musée des Familles. Quanto às revistas, elas são numerosas. As mais ilustres foram: a Revue de Paris, que publicou artigos sobre os salões de arte (Salon); a Revue des Deux

pareceres reescrevendo-os em seu estilo. François Brunet (2006, p. 89-99) lista alguns destes colaboradores anônimos: Antoine Elwart, Allyre Bureau, Hector Berlioz, Adolphe Adam e Ernest Reyer.

${ }^{5}$ Durante os primeiros anos de Gautier no La Presse, ele se ausentou em quatro ocasiões, durante grandes viagens: Espanha (maio-outubro de 1840), Argélia (julho-setembro de 1845), Itália (agosto-novembro de 1850) e Turquia e Grécia (junho-outubro de 1852). Com base nestas viagens, Gautier escreveu suas célebres narrativas de viagem que enviava ao editor Girardin em forma de folhetim durante sua ausência de Paris. Sobre a narrativa de viagem à Espanha conferir Autor (2014).

${ }^{6}$ Conforme demonstram as referidas pesquisas da especialista, Gautier jornalista escreveu mais de 1460 folhetins teatrais, 660 críticas de arte (e de Salons) e 127 críticas literárias, além das 592 ocorrências de outras publicações de variados gêneros na imprensa e das 150 republicações de seus próprios textos, totalizando 2993 artigos escritos, precisamente, em 93 publicações periódicas (revistas, magazines e jornais). Nos quase vinte anos de contribuição para o diário La Presse, Gautier escreveu 769 artigos inéditos para a rubrica folhetinesca dos espetáculos. Já para o Moniteur foram produzidas 592 críticas teatrais. Cf. "Tableau de synthèse de la répartition de l'oeuvre de Théophile Gautier dans la presse" (LAVAUD, 2008). 
Mondes, para a qual enviou uma série de artigos sobre sua "Voyage en Espagne"; e Le Journal des demoiselles, que concentra a maior parte dos lançamentos e republicações de suas poesias (LAVAUD, 2008). Reforçando a presença de Gautier na imprensa francesa do século XIX, destaca-se o lançamento do periódico fundado por ele e Lassailly, Ariel, journal du monde élégant, entre março e maio de 1836, além de sua participação no Artiste como redator e diretor de redação, de dezembro de 1856 a março de 1859. Finalmente, é preciso lembrar que grande parte de suas novelas, romances e poesias - na verdade, quase a totalidade, com exceção de Mademoiselle de Maupin (1835) - foi publicada, primeiramente, na imprensa periódica, antes de ser editada em livros (SOCIÉTÉ THÉOPHILE GAUTIER, 2020).

\section{O jornal, a revista teatral e a literatura: a rotina da crítica folhetinesca e sua criação}

O grande volume de espetáculos a ser comentado todas as segundas-feiras, dia fixo de seu folhetim no La Presse, realmente se transformava em lamentações e reclamações constantes nas críticas de Gautier. Algumas vezes tal protesto era ornado pelo humor e, frequentemente, o crítico ironizava o panorama teatral parisiense por causa da desproporção entre o enorme volume e a baixa qualidade dos espetáculos. Este "dilúvio" teatral é denunciado em vários $\operatorname{artigos}^{7}$ e é definido pelo folhetinista como um "complô de diretores contra os críticos, que consiste em encenar todas as peças novas ao mesmo tempo" (GAUTIER, La Presse, 19 de março de 1838 , tradução nossa) ${ }^{8}$

Começamos este artigo sem esperar poder jamais terminá-lo. [...] a semana foi desastrosa; somente os títulos das peças encenadas dariam um folhetim de seis colunas: o teatro das Variétés ofereceu quatro peças só ele; julguem o resto. Os críticos estão sob grande pressão. Desde domingo, emagrecemos quase um quilo, só tivemos tempo de dormir no teatro, e fazendo nosso folhetim. ${ }^{9}$ (GAUTIER, La Presse,19 de março de 1838, tradução nossa)

\footnotetext{
${ }^{7}$ Nestes primeiros anos como folhetinista, em especial, nos artigos de 23 de outubro de 1837, 26 de fevereiro de 1838, 24 de dezembro de 1838 e 14 de fevereiro de 1843, por exemplo.

8 “complot des directeurs contre les critiques qui consiste à faire jouer toutes les pièces nouvelles à la fois". Este excerto de Gautier, assim como os demais do autor citados neste estudo, têm tradução nossa.

9 "Nous commençons cet article sans espérer de le pouvoir finir jamais. [...] la semaine a été désastreuse ; le titre seul des pièces jouées ferait un feuilleton de six colonnes : le théâtre des Variétés a fourni quatre pièces pour son 
Paralelamente a esta ativa e heterogênea participação na imprensa, a expressiva quantidade de folhetins sobre os espetáculos marca diferentes atualidades teatrais e mesmo culturais, ao longo das décadas em que Gautier colaborou para os periódicos, sendo possível extrair deste volume de folhetins aspectos que orientam a crítica e a escrita de Gautier folhetinista. Primeiramente, quanto à estrutura dos folhetins, em geral, esses não seguem a fórmula tradicional de análise dos aspectos da cena e da música, organizada por uma introdução, um preâmbulo e um resumo da intriga. ${ }^{10}$ Entretanto, sempre preocupado com seu público, Gautier parece jogar com a expectativa do leitor, razão pela qual emprega, com bastante frequência, outro modelo de resenha. É o que François Brunet (2006) chama de resenha "mista" ou "romanesca", caracterizada por técnicas narrativas como descrições e diálogos pelos quais os aspectos do espetáculo são tratados ao longo da narração, que faz a vez da análise. De um modo ou de outro, é comum em seu folhetim que a intriga seja apresentada por meio do comentário detalhado, construído como um conto, por exemplo. Muitas vezes, tal narração aparece desprovida de uma nítida avaliação, modo pelo qual Gautier contesta ironicamente, na maior parte dos casos, o mérito da peça: seu silêncio alarmante anuncia já sua opinião desfavorável. Esta fórmula de análise abordava geralmente a descrição da intriga, de situações dramáticas, da encenação, da psicologia dos personagens e da interpretação da peça, sempre evidenciando e desvendando as técnicas da encenação, algumas vezes, por meio de uma descrição caricatural do personagem, dos objetos e da decoração. É o caso do excerto que segue.

O que é o capitão Roquefinette? Este nome se percebe a vários quilômetros de distância, pelo repelido círculo de feltro cinza sobre a orelha, pela pena vermelha varrendo os tetos, pelas botas funil, pelo florete extravagante e pelo jogo de quadril. - De fato, o capitão Roquefinette é um bravo, valente, um fanfarão profissional, um capitão reformado. Esta posição pouco lucrativa the dá infinitas privações de almoços e comensais, mesmo que ele ronde a região de Versalhes mostrando os ares mais refinados, nenhum coração é suspenso pelos ganchos do seu bigode e o grande rei não sente nenhuma necessidade de

compte ; jugez du reste. Les critiques sont sur les dents ; depuis dimanche, nous avons maigri de sept quarterons, et nous n'avons eu le temps de dormir qu'au théâtre et en faisant notre feuilleton.".

${ }^{10}$ Ver a crítica sobre Théophile Gautier folhetinista, particularmente François Brunet (2006) e Giovanna Bellatti (2008). 
se afeiçoar à sua pessoa. O mais honesto dos seus rendimentos é o de ser testemunha e assistente nos duelos. No entanto, um dia, caiu-lhe da janela, em cima do seu nariz - o quê? - um buquê? - precisamente. Como os buquês não se jogam eles mesmos pelas janelas, este buquê deve ter sido lançado por um alguém, ou talvez por uma alguém. ${ }^{11}$ (La Presse, 30 de outubro de 1843)

Conforme a descrição pitoresca mostra, a pena Gautier é capaz de capturar a cena como uma pintura, ${ }^{12}$ de modo inventivo, emancipado e desenvolto, menos voltada ao pragmatismo do que à liberdade de um discurso heterogêneo - literário, pictórico, factual -, em forma de mosaico, que o torna, em certa medida, surpreendente.

\section{Princípios e traços, da arte à poética folhetinesca}

Distinguindo-se por uma escrita polifônica, Gautier folhetinista, traz do poeta uma tendência lírica e, também, ficcional, do contista-romancista, que se destaca no rodapé, em dissonância com as informações dadas no alto da página do jornal. Em especial, o recurso a esta linguagem poética está ligado às apreciações dos espetáculos musicais, conforme François Brunet (2006) já demonstrou em seu estudo sobre o autor e a música. Tal linguagem, entretanto, também aparece nas descrições picturais de objetos, personagens, cenas e interpretações que lhe agradam, ou ainda em digressões que derivam destas descrições. Assim, sua cantora predileta do teatro italiano, Giulia Grisi, na ocasião do espetáculo a ela dedicado, é descrita como "armada com sua foice de ouro, a cabeça coroada de verbena e o olhar perdido no brilho prateado da lua". Nesta noite, na ópera Norma, "ela disse com serena melancolia, como uma

\footnotetext{
11 "Qu'est-ce que le capitaine Roquefinette? Ce nom sent de plusieurs kilomètres à la ronde le feutre gris repoussé sur l'oreille, la plume rouge balayant les plafonds, les bottes en entonnoir, la rapière extravagante et le poing sur la hanche. - En effet, le capitaine Roquefinette est un brave, un vaillant, un tranche-montagne de profession, un capitaine à la réforme. Cette position peu lucrative lui rapporte une infinité d'absences de déjeuners et de dîneurs il a beau rôder autour de Versailles en se donnant les airs les plus raffinés, nul cœur ne se suspend aux crocs de sa moustache, et le grand roi ne se sent aucun besoin de l'attacher à sa personne. Le plus clair de son revenu est de servir de témoin et de second dans les duels. Cependant, un jour, il lui tombe d'une fenêtre, juste en plein sur le nez - quoi? - un bouquet? - précisément. - Comme les bouquets ne se jettent pas eux-mêmes par les fenêtres, ce bouquet a dû être lancé par quelqu'un, ou plutôt par quelqu'une.".

${ }^{12}$ Gautier tinha um gosto especial pelas belas-artes. Ele estudou com o pintor Rioult e teve boa formação neste ramo artístico.
} 
bela noite de verão, a deliciosa ária de Casta Diva, que desabrochou em um rojo prateado no céu azul". No fim do espetáculo, "o véu negro recaiu sobre sua nobre fronte, o florido bombardeio começou. Foi um disparo de buquês e de coroas" (La Presse, 24 de fevereiro de 1845). ${ }^{13}$ Em relação à arte dramática, a partir da leitura contínua dos folhetins, sob a pena de Gautier percebe-se o intuito insistente do crítico de mostrar as possibilidades de se realizar, no momento presente do folhetinista, um teatro que reunisse as formas grotescas e populares do real e medidas estéticas que ampliassem o efeito do que estava sendo representado. Devido a esta consciência artística, Gautier permanecerá um artista e jornalista fiel a seus ideais de arte, logo, muito pouco influenciado por esperanças de complacência, não raro cultivadas pelo círculo teatral e musical de então. Nos primeiros anos como crítico dos espetáculos, ele apontava a decadência estética do teatro francês de seu tempo, já que as direções dos teatros e os autores resistiam ainda às inovações propostas pela voga romântica, mas também por causa da vulgarização da ópera com a popularização das óperas-cômicas e dos vaudevilles.

As dificuldades do crítico aumentam todos os dias, de domingo em domingo. O folhetim torna-se, cada vez mais, impossível. O mesmo vaudeville é perpetuamente encenado em todo lugar sob nomes bem pouco diferentes, e com os atores fazendo todos os esforços para conservar sua própria individualidade ao invés de representar o personagem de que são encarregados, o teatro torna-se uma monotonia desesperadora; fica-se logo farto de ver o Sr. fulano ou ciclano com seus hábitos e seus tiques que ele conserva preciosamente [...].

Há tanto tempo, ah! A arte e a poesia desapareceram do teatro. O teatro, este charmoso refúgio da fantasia, habitado por uma nação à parte com modos excepcionais, [...] hoje não é mais que uma empresa industrial, como uma fábrica de açúcar de beterraba ou uma sociedade de betume (fundo social: um milhão). ${ }^{14}$ (La Presse, 30 de abril de 1838)

\footnotetext{
13 “armée de sa faucille d'or, le front couronné de verveine et l'œil perdu dans la lueur argentée de la lune”; "elle a dit avec une mélancolie sereine, comme une belle nuit d'été, ce délicieux air de Casta Diva, qui s'épanouit en une fusée d'argent dans le ciel d'azur" ; e "le voile noir s'est abaissé sur sa noble tête, le bombardement fleuri a commencé ; ça été une mitraillade de bouquets et de couronnes".

14 “L'embarras du critique augmente tous les jours; de dimanche en dimanche, le feuilleton devient de plus en plus impossible ; le même vaudeville se joue perpétuellement partout sous des noms à peine différents, et les acteurs, faisant tous leurs efforts pour conserver leur individualité propre au lieu de représenter le personnage dont ils sont chargés, le théâtre devient d'une monotonie désespérante; on se lasse bientôt de voir M. tel ou tel avec ses habitues et ses tics qu'il conserve précieusement [...].

Depuis bien longtemps, hélas! L'art et la poésie ont disparu du théâtre ; le théâtre, ce charmant refuge de la fantaisie peuplé par une nation à part avec des mours exceptionnelles, [...] n'est plus aujourd'hui qu'une entreprise industrielle, comme une fabrique de sucre de betteraves ou une société pour le bitume (fond social : un million).".
} 
Considerando a imagem do jovem Gautier do colete vermelho, ao lado do também jovem dramaturgo Victor Hugo, na ocasião da batalha de Hernani, em 1830, nem é preciso assinalar o partidário do teatro mais moderno e romântico que ele foi. Isto é, partidário de uma arte dramática renovada, livre das amarras formais clássicas e que representasse os conflitos dos indivíduos na modernidade. Estes princípios o incitavam, frequentemente, a censurar o teatro feito 'à moda antiga', em favor de dramaturgos à altura do drama moderno e em detrimento dos autores em evidência que não contribuíam quase nunca para as artes dramática e lírica originais, tal como Paul de Kock, "que é, não sabemos muito o porquê, o escritor mais popular da França, cujo sucesso eclipsa o de Victor Hugo, d'Alfred de Musset, de George Sand e de todos os gênios superiores da época [...]"15 (La Presse,16 de julho de 1838). Suas concepções artísticas explicam também a aversão ao uso do estilo clássico, da tragédia e da forma em versos alexandrinos, aspecto que Gautier sempre assinalava e criticava em suas revistas, uma vez que não encontrava beleza nos pretendidos versos clássicos dos dramaturgos contemporâneos a ele. Ademais, tais versos não ofereciam nada de novo e nem de legítimo à ação dramática, a qual era sempre monótona e cansativa.

Consequentemente, os folhetins de Gautier traziam um discreto fundo pedagógico, que reflete efeitos de humor e ironia em sua escrita, como que para advertir o leitor e espectador parisiense sobre a superficialidade artística dos espetáculos da moda, ou que ainda estavam na moda. Por um suposto tom de benevolência e polidez, quase sempre irônico, mas que ao menos suscitava humor, o folhetinista procurava avaliar o mérito dos autores e de suas obras mais pela qualidade artística, pelo valor e pela originalidade estética, dramatúrgica e musical das obras e menos pelo sucesso popular de certos gêneros e peças ou pela experiência dos dramaturgos. Um exemplo evidente desta 'pedagogia' é a resistência dele aos vaudevilles e a certas óperascômicas, sobretudo aquelas de Eugène Scribe, autor de diversas peças de sucesso, em Paris e no exterior, inclusive no Brasil. Gautier sempre contestou a facilidade, a falta de estética, os clichês e a inverossimilhança dos temas e dos cenários de Scribe. No folhetim dedicado a $L a$

\footnotetext{
15 "qui est, nous ne savons trop pourquoi, l'écrivain le plus populaire de France, et dont le succès éclipse celui de Victor Hugo, d'Alfred de Musset, de George Sand et de tous les génies supérieurs de l 'époque [...].".
} 
Barcarolle, ópera-cômica inédita de Scribe e de Auber, o crítico é incisivo, sobretudo no último parágrafo da citação a seguir, valendo-se do efeito irônico que otimiza pela antífrase os verdadeiros méritos do dramaturgo, segundo a opinião do folhetinista.

De acordo com os folhetinistas eruditos, parece que a Barcarolle já foi encenada considerável número de vezes com diferentes títulos; o Sr. Scribe, em colaboração com o Sr. Varner, teria escrito um vaudeville intitulado: $a$ Chanson ou l'intérieur d'un bureau, cujo assunto é idêntico ao da Barcarolle. Mas, o que importa?! As peças não são elas sempre as mesmas; e, além disso, por que mudar? Não é melhor uma boa situação, bem usada, bem conhecida, bem trivial, que não exija mais que meia atenção distraída da parte dos espectadores [...] - A Barcarolle não causa nenhuma inflexão intelectual. Desde a primeira palavra sabe-se a última [...].

Coisa singular! O Sr. Scribe, sem nova concepção, sem aprofundar o pensamento, sem estilo severo, sem força cômica, sem trato e sem palavras conseguiu fazer obras que são ainda as mais agradáveis de todas estas que compõem a provisão dos teatros. ${ }^{16}$ (La Presse, 28 de abril de 1845)

Com esta breve explanação e os exemplos vistos, nota-se que Gautier foi um crítico dedicado à sua função, mas também aos seus princípios e concepções. Reiteramos, com Patrick Berthier (2004, p. 443), a dura rotina que era para o poeta seguir os espetáculos dos principais teatros dramáticos e líricos de Paris e fazer suas revistas todas as semanas como uma obrigação profissional, de acordo com o ritmo e a atualidade da intensa vida cultural e de entretenimento parisiense. De todo modo, como folhetinista, ele se distingue, na perspectiva dos estudos literários atuais, pela originalidade do seu estilo e de sua escrita inovadora e polifônica; algumas vezes uma escrita lírica, outras, mordaz. A tonalidade de seu estilo é conscientemente escolhida e trabalhada de modo a extrair de termos simples, e até mesmo familiares, efeitos poéticos,

\footnotetext{
16 "Il paraît d'après les feuilletonistes érudits que la Barcarolle a déjà été jouée un nombre de fois considérable sous différents titres; $M$. Scribe, en collaboration avec M. Varner, aurait donné un vaudeville intitulé : la Chanson ou l'intérieur d'un bureau, dont le sujet est identiquement celui de la Barcarolle. Mais qu'importe! Les pièces ne sont-elles pas toujours les mêmes; et d'ailleurs pourquoi changer? Ne vaut-il pas mieux une bonne situation, bien usée, bien connue, bien triviale, qui n'exige de la part des spectateurs qu'une demi attention distraite [...]. La Barcarolle ne cause aucune courbature intellectuelle. - Dès le premier mot vous savez le dernier [...]. Chose singulière! M. Scribe, sans nouveauté de conception, sans profondeur de pensée, sans sévérité de style, sans force comique, sans trait et sans mots, parvient à faire des ouvrages qui sont encore les plus agréables de tous ceux dont se compose la fourniture des théâtres.".
} 


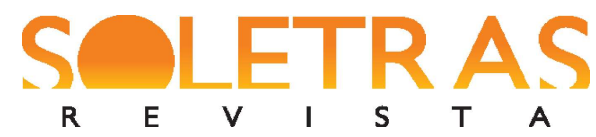

N. $40-2020.2$ - PRISCILA RENATA GIMENEZ

cômicos e irônicos, diversificados e inesgotáveis, tal como se apresentam as possibilidades de criação no rodapé do jornal midiático.

Como artista romântico, profundamente consciente e observador das transformações de sua época, Gautier reprova a parcela do teatro antigo ainda presente, tal como Hector Berlioz censurava a inanidade musical. Além disso, ele contesta a própria edificação do suporte, que faz a mediação entre ele - enquanto folhetinista/jornalista - e o leitor, bem como questiona as formas de escrita destas materialidades midiáticas, isto é, o jornal e o folhetim. Martine Lavaud (2011) classifica este tipo de abordagem como uma das "categorias de invenções estéticas", definida como "a arte da diversão, da farsa, da encenação derrisória de si"17 (p. 1172, tradução nossa), conforme detalharemos a seguir.

\section{Contornos de uma poética edificada pela ironia}

No folhetim teatral, Théophile Gautier parece usar de toda liberdade proporcionada pelo espaço de criação essencial, que foi o rodapé do jornal no século XIX. Habilidoso e sob a ação de sua pena de escritor multifacetado, como folhetinista, ele põe em prática uma escrita construída pela ironia literária, ${ }^{18}$ ou seja, o princípio de colocar sua escrita à distância de si mesma e de ser construída a partir de um "exercício de linguagem” que retoma outras formas e estilos. ${ }^{19}$ Em relação ao suporte do folhetim, o jornal, tal escrita contrasta com a lógica do discurso sério e factual, próprio da imprensa, por suas formas polifônica, metadiscursiva e, até mesmo, fantástica.

Este posicionamento legitima uma escrita, em certa medida, experimental e sustenta uma elaboração literária com desdobramentos para além do assunto teatral, tornando-a polissêmica e metadiscursiva e que permite transições entre a ficção e o referencial, entre a metáfora e a ironia, entre poesia, romance e folhetim, enfim, entre texto, escritor e suporte. Desde a manifestação da ironia em um primeiro nível, dada pela antífrase, a postura de ironista

\footnotetext{
17 “catégories d'inventions esthétiques"; "l'art de la diversion, du canular, la mise en scène dérisoire de soi".

${ }^{18}$ Dentre os numerosos estudos da crítica de Gautier, Françoise Court-Perez (1998) propõe um estudo sobre a ironia na obra do autor jornalista, especialmente de sua prosa.

${ }^{19}$ A tese da ironia literária em Théophile Gautier folhetinista já foi desenvolvida e demonstrada em relação à crítica aos espetáculos líricos. Conferir Autor (2018).
} 
assumida por Théophile Gautier no bas de page é otimizada em sua escrita pelo humor que normalmente resulta deste posicionamento, sempre associado a outros procedimentos como o jogo de palavras, ambiguidade, o pastiche, etc. Mesmo que o assunto teatral seja essencialmente efêmero, como as notícias do jornal, o crítico arquiteta em sua escrita folhetinesca formas que privilegiam dualidades e contrastes, manifestando sua elaboração literária. Os sinais desta presença aparecem diluídos em seu texto por estratégias inusitadas, por exemplo, como se constata no fim da análise do segundo ato do vaudeville de Dumanoir, Dennery e Claiville, Paris voleurs.

P. S. - Este quadro é divertido e verdadeiro, mas o que há de mais belo e o que os atores não disseram é que ele mesmo não é mais que a imitação pura e simples, a cópia quase literal, de um vaudeville chamado: L'Art de rentrer dans son bien, o qual foi encenado ano passado, com muito sucesso [...]. Os Srs. Dumanoir, Dennery e Clairville provavelmente quiseram unir o exemplo à regra. A coisa, explicada dessa maneira, seria muito engenhosa. ${ }^{20}$ (La Presse, 22 de julho de 1844, grifo nosso)

O trecho mostra bem a escrita ambígua do folhetinista. Interrompendo a análise dos atos do vaudeville, Gautier oferece uma explicação mordaz para o sucesso do segundo ato, que é destacada de sua apreciação. Contudo, a última frase do trecho conserva, na explicação, uma dualidade: que "coisa" é, de fato, "muito espirituosa", a malícia dos autores do vaudeville ou a estratégia do folhetinista, de sugerir o plágio dos dramaturgos por uma frase que se refere aos dois artifícios ao mesmo tempo? A singularidade desta passagem está exatamente na aparente sutileza da dualidade nela inscrita, assim como no artifício do folhetinista que simula falar de um aspecto do espetáculo, revelando, porém, uma estratégia de sua própria escrita. A dissimulação aparece já no início do folhetim, quando o crítico parece se vigiar, na intenção de se centrar somente na matéria teatral: "Seis quadros, quer dizer, seis atos, - e temos ainda dois ou três que nos esperam! Apressemo-nos para entrar no assunto, se não quisermos ser pegos

\footnotetext{
20 "N. B. - Ce tableau est amusant et vrai ; mais ce qu'il y a de plus beau, et ce que les auteurs n'ont pas dit, c'est qu'il n'est lui-même que la contrefaçon pure et simple, la copie presque littérale d'un vaudeville intitulé : L'Art de rentrer dans son bien, lequel vaudeville a été joué, l'année dernière, avec beaucoup de succès [...] MM. Dumanoir, Dennery et Clairville ont probablement voulu joindre l'exemple au précepte. La chose, expliquée de cette façon, serait fort spirituelle.".
} 
desprevenidos." ${ }^{21}$ (ibidem). Entretanto, o fato de registrar o citado lembrete em seu artigo invalida sua própria proposta, pois, ao invés de empreender um ritmo e um método objetivos em seu texto, o folhetinista se deixa guiar pelo traço sinuoso de sua pluma.

A marca da obliquidade se manifesta também na organização e na liquidez da prosa de Gautier. Seu deleite ao falar de arte é revelado tanto no volume de linhas que são dedicadas ao tema, quanto no modo de se referir aos espetáculos medíocres. O excerto abaixo é uma amostra do último caso.

No momento, temos que deixar escorrer uma terrível enxurrada de vaudevilles. - Acontece-nos, às vezes, de ter de tratar de questões de arte e de literatura, e deixamo-nos enredar, um pouco, por um traçado fora de nosso habitual. - Shakespeare prejudicou estes senhores do flon-flon ${ }^{22}$ e não teremos muito espaço para lhes dar. Mas o paquete vai levar Hamlet, Otelo, Romeu e Julieta, Macbeth, Werner, todas estas obras-primas que roem o espaço das análises e das resenhas. Agora, teremos o prazer de examinar conscienciosamente se tal vaudeville é mais detestável que outro, e, sobre nossos palcos de teias de aranha, passaremos por uns depois pelos outros para saber - grave questão:

Qual é a diferença entre o vazio e o nada? ${ }^{23}$ (La Presse, 20 de janeiro de 1845)

O excerto mostra que, após uma apreciação de Romeu e Julieta, apresentada no teatro inglês, o folhetinista ainda tem que tratar dos vaudevilles que, segundo ele, não teriam uma apreciação, mas iriam "escoar" pelo espaço que lhe restava ainda do folhetim. A metáfora da passagem provoca o humor, porque é associado à antífrase, quando Gautier simula acusar

\footnotetext{
21 "Six tableaux, c'est-à-dire six actes, - et nous en avons encore deux ou trois autres qui nous attendent! Hâtonsnous d'entrer en matière, si nous ne voulons pas trouver pris de court.".

${ }^{22}$ Alcunha depreciativa para vaudeville.

${ }^{23}$ Ressaltamos que, em português, o sentido irônico da pergunta feita pelo folhetinista não pode ser reproduzido completamente, pois não temos palavras equivalentes para reproduzir o efeito de sentido do uso associado dos termos néant e rien. "Nous avons à présent à couler une assez effrayante lessive de vaudevilles. - Il nous arrive si peu souvent d'avoir à traiter des questions d'art et de littérature, que nous nous sommes laissé un peu entraîner hors de notre sillon habituel. - Shakespeare a fait tort à ces messieurs du flon-flon, et nous n'aurons pas beaucoup de place à leur donner. Mais le paquebot va remporter Hamlet, Othello, Romeo et Juliet, Macbeth, Werner, tous ces chefs-d'œuvre qui rognent l'espace aux analyses et aux rendus comptes; maintenant, nous allons avoir le loisir d'examiner consciencieusement si tel vaudeville est plus détestable qu'un autre, et sur nos plateaux de toiles d'araignée nous les peserons les uns après les autres pour savoir, - question grave, Entre néant et rien, quelle est la différence?".
} 


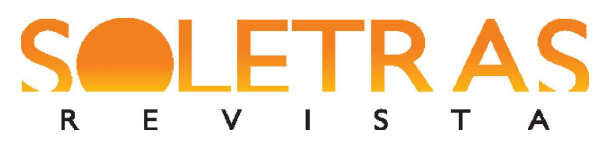

N. $40-2020.2$ - PRISCILA RENATA GIMENEZ

Shakespeare de ter reduzido o espaço destinado aos vaudevilles. Ao contrário dos versos do drama shakespeariano, os vaudevilles não enriqueceriam a arte, e não ofereceriam nada de interessante, mesmo à revista teatral. Para denunciar tal inutilidade, o folhetinista coloca, então, a pergunta retórica: já que os espetáculos são desprovidos de essência artística, de originalidade, e mesmo de entretenimento, a verdadeira questão seria, então, 'por que falar deles?'.

A parte final deste trecho traz ainda um metadiscurso camuflado, uma vez que o folhetinista assinala, o "prazer de examinar conscienciosamente" como se apresentara a sequência da apreciação dos vaudevilles; isto é, o dever refutado de falar destes espetáculos o orienta a não alongar seu folhetim sobre "coisa nenhuma" nem sobre "nada". De todo modo, como folhetinista dos espetáculos, se ele deve fazê-lo, a melhor solução parece ser abordar os vaudevilles com toda sinceridade, por meio do processo de falar o mínimo sobre eles. Por isso mesmo, o crítico passa diretamente à apreciação do mérito dos dois vaudevilles apresentados no teatro Palais-Royal, sem dar o costumeiro resumo alongado das peças. Ele anuncia prontamente que neste teatro "colocamos dois epitáfios, um sobre Averse, e o outro sobre Fiancre et le Paraplue" ${ }^{24}$ (GAUTIER, ibidem), os dois vaudevilles em questão.

É importante reiterar que o discurso discretamente provocador se manifesta, muitas vezes, em digressões propriamente ditas, já mencionadas anteriormente, às quais o folhetinista recorre em vista de contornar a revista teatral, extraindo, deste recurso, efeitos como censura, humor, estilo e ambiguidade, autorizados e legitimados pelo discurso amplamente literário permitido no rodapé do jornal. A consciência desta posição distanciada da escrita torna possível a modulação da elaboração dos folhetins, segundo a reflexão subjacente intencionada. Mininarrativas, memorandus e perfis, por exemplo, são recursos do crítico, que vê seu objeto de crítica e seu suporte de escrita e publicação "com um sorriso semi-irônico" (GAUTIER, La Presse, 8 de fevereiro de 1843). Um exemplo é o da publicação de 10 de dezembro de 1837, no qual o folhetinista criou um personagem chamado "um espectador". Ao dar voz ao personagem, em quatro das seis colunas do folhetim, Gautier constrói sua crítica, de forma indireta e irônica, pois, do discurso do tal espectador, sobressai uma crítica impetuosa do próprio folhetinista, marcada pelo sentido inverso dos elogios feitos pelo personagem a uma "nova tragédia". Assim

\footnotetext{
24 “"nous avons à poser deux épitaphes, l'une sur l'Averse, et l'autre sur le Fiancre et le Paraplue".
} 
se explica ele, introduzindo a análise emitida, pelo "espectador", com "entusiasmo" e com "um calor de hipotipose e um ardor de metáforas", ${ }^{25}$ que Gautier suposta e propositalmente quis conservar:

Uma nova tragédia.

Anuncia-se a próxima apresentação, no [teatro] Odéon, de uma tragédia romântica mais audaciosa, mais nova, mais extraordinária, mais esplêndida que todas as tentativas mais temerárias que, há dez anos, se ousou arriscar, em todos os teatros de Paris. É uma bela resposta que o Odéon prepara para os jornais que lhe reprovavam ter inaugurado, sob velhos auspícios, um teatro destinado a encorajar as inovações e os jovens talentos. Os ensaios desta obra aconteceram no maior segredo. Mas, neste século da publicidade, é difícil que um segredo seja guardado até o fim. Houve uma testemunha indiscreta. Este indiscreto nos tomou por confidente e partilhamos a confidência apenas com o público, a quem, por sua vez, pedimos mais discrição que mostramos nós. São sempre assim as confidências. ${ }^{26}$ (La Presse, 10 de dezembro de 1837)

Igualmente, as reclamações do enorme volume de espetáculos constituíam sempre boas ocasiões de digressões, como já demonstrado acima, e, não raro, eram associadas à ficcionalização de uma situação, à criação de um personagem ou de uma anedota. No caso do folhetim de 14 de fevereiro de 1843, a seguir, Gautier cria uma anedota sob o pretexto de que o folhetinista não tem "o precioso dom da ubiquidade". Retomando a caricatura dos "jeunes critiques blonds" (La Presse, 26 de fevereiro de 1838), quer dizer, um tipo de crítico inexperiente - expressão emprestada da monografia da imprensa parisiense de Honoré de Balzac (1844, p. 173) -, o folhetinista explica:

25 “[...] une chaleur d'hypotypose et une ardeur de métaphores [...]".

26 "Une tragédie nouvelle. On annonce la représentation prochaine, à l'Odéon, d'une tragédie romantique, plus hardie, plus nouvelle, plus inouïe, plus étourdissante qu'aucune des tentatives les plus téméraires qu'on ait osé risquer, depuis dix ans, sur aucun des théâtres de Paris. C'est une belle réponse que l'Odéon prépare aux journaux qui lui reprochaient d'avoir inauguré, sous des auspices vieillis, un théâtre destiné à encourager les innovations et les jeunes talents. Les répétitions de cet ouvrage ont lieu dans le plus grand secret. Mais, dans ce siècle de publicité, il est bien difficile qu'un secret soit gardé jusqu'au bout. Il y a eu un témoin indiscret; cet indiscret nous a pris pour confident; et nous ne faisons part de sa confidence qu'au public, à qui nous demandons, à son tour, plus de discrétion que nous n'en montrons nous-même. C'est toujours comme cela que se font les confidences.". 
Por mais que sejamos o folhetinista mais consciencioso do mundo, é impossível assistir, ao mesmo tempo, a quatorze primeiras representações. Nestes dias, os jeunes critiques blonds têm valor exorbitante. Na falta deles, procuramos introduzir na literatura pessoas das mais respeitáveis. ${ }^{27}$ ( $\mathrm{La}$ Presse, 14 de fevereiro de 1843)

A partir desta constatação, Gautier passa a contar com uma singular colaboração que teve de "uma espécie de negro astuto, chamado Francesco Abdallah Pergialla, o qual estava a nosso serviço nesta época". ${ }^{28}$ (GAUTIER, ibdem). Na verdade, este tipo é um personagem ficcional que Gautier tomou emprestado de uma de suas novelas, La Mille e Deuxième Nuit, ${ }^{29}$ mas sem fazer nenhuma referência ao conto. Além da coincidência dos nomes, o suposto colaborador do folhetim pode, sem dúvida, ser identificado com o personagem da novela, pois, no conto, o narrador personagem, um "literato", tal como o folhetinista, descreve AdolfoFrancesco-Pergialla como seu empregado "abissínio". ${ }^{30} \mathrm{Se}$, numa primeira leitura do folhetim, não nos lembramos de Pergialla ou não o reconhecemos do conto fantástico - o que é o mais provável -, temos a impressão de que se trata de um tipo real, que presta serviço ao folhetinista fazendo a resenha da noite no teatro Ambigu-Comique. Contudo, a anedota se revela, à medida que ele/o escritor/ocrítico reproduz o resumo da noite que Pergialla lhe teria feito. Nota-se, ainda, que os aspectos levantados na crítica não correspondem, minimamente, a uma apreciação crível, mas, talvez, a um tipo de avaliação próxima àquelas típicas dos "jeunes critiques blond", caracterizados como um tipo negador, trapaceiro ou adulador. ${ }^{31}$ Assim, reporta a seu leitor a narração de Pergialla:

\footnotetext{
27 "On a beau être le feuilletoniste le plus consciencieux du monde, il est impossible d'assister à la fois à quatorze premières représentations. Ces jours-là les jeunes critiques blonds sont hors de prix. À leur défaut, on tâche d'introduire en littérature les personnes les plus respectables.".

${ }^{28}$ Patrick Berthier nas Ouvres Complètes IV (2012, p. 79) de T. Gautier, lembra que este personagem fora citado em 5 de abril de 1842. "une espèce de brigand nègre nommé Francesco Abdallah Pergialla, au service duquel nous étions à cette époque".

${ }^{29}$ Novela lançada no Musée des familles de agosto de 1842 e no Compilateur de 31 de agosto de 1842, editada na antologia Romans et contes, pela editora Charpentier, em 1863.

30 "Adolfo-Francesco-Pergialla, espèce de brigand abyssin au service duquel j'étais alors" (GAUTIER, 1863, p. 139).

${ }^{31}$ Termos extraídos do subtítulo consagrado à caracterização dos jeunes critiques blonds, "Le négateur, le faceur, le thuriféraire" (BALZAC, 1844, p. 173-176).
} 
Ele me contou que se tratava de um senhor que queriam matar e que, efetivamente, mataram, porém, ao fim de duas horas. Ele se espantou muito com a lentidão atribuída a esta operação e achava que a peça teria sido muito mais bonita se tivessem degolado logo o senhor.

Ele também gostaria que os atores fossem maiores. [...] "Imagine, mestre, nos dizia ele [...]. É engraçado! O carrasco vem com uma vara da grossura de um dedo e plaft!, e pleft!, ele lhes dá até que a carne fique picadinha. Oh! E as caretas estranhas! [...]." ${ }^{\prime 2}$ (La Presse, 14 de fevereiro de 1843)

De fato, não é gratuitamente que o folhetinista transcreveria uma sinopse tão acre e rústica como essa. Com a intenção de criar a imagem e o caráter do seu auxiliar para o leitor, Gautier reproduz, até mesmo, sua linguagem fácil, direta e austera, repleta de formas exclamativas. A pitoresca narrativa da colaboração de Pergialla termina com sua demissão, a qual o folhetinista justifica apresentando uma declaração pouco convencional e pouco lógica do suposto colaborador.

Ele achou seu trabalho literário rude demais, pois quase não há blancs que possam aguentar o folhetim e, depois de se submeter a mais uma apresentação, munido de um certificado assim concebido, ele nos deixou:

"Certificamos que Abdallah, em anexo, é preguiçoso, bêbado, ladrão, brigão e possui uma coleção completa de vícios. A única qualidade que tem é de ser um bom negro, o que garantimos tendo visto suportar a chuva sem ficar cinza, integridade que ele não mantém diante do vinho.". ${ }^{33}$ (La Presse, 14 de fevereiro de 1843)

\footnotetext{
${ }^{32}$ Não é possivel dizer precisamente se esta narrativa de Pergialla é imaginária ou se ele fala de algum espetáculo do Ambigu-Comique. Porém, podemos esclarecer que nas semanas anteriores, o teatro apresentou as seguintes peças Livret, Madeleine, Les Dettes, L'Ouvrier e Paul et Virginie. "Il me raconta qu'il s'agissait d'un monsieur qu'on voulait tuer, et qu'effectivement on tuait, mais au bout de deux heures. Il s'étonnait beaucoup de la lenteur apportée à cette opération, et prétendait que la pièce eût été beaucoup plus jolie si l'on eût égorgé le monsieur tout de suite. Il aurait aussi désiré que les acteurs fussent plus grands. [...] 'Figurez-vous, maître, nous disait-il [...]. C'est drôle! Le bourreau vient avec une baguette grosse comme le doigt, et v'li, et v'lan, il leur en donne tant que la chair soit comme une pâte. Oh! Les singulières grimaces! [...].' ”.

33 "Il trouva son service littéraire trop rude, car il n'y a guère que les blancs qui puissent résister au feuilleton, et après avoir subi une autre représentation, il nous quitta, muni d'un certificat ainsi conçu :

'Nous certifions que l'Abdallah ci-joint est paresseux, ivrogne, voleur, querelleur, et possède une collection de vices complète. La seule qualité qu'il ait, c'est d'être noir bon teint, ce que nous garantissons, l'ayant vu supporter la pluie sans devenir gris, propriété qu'il n'a pas avec le vin. .'”.
} 
A platitude do teatro contemporâneo, como comentado anteriormente, também constitui uma válvula de escape da qual o crítico se serve para autorizar-se ao prazer de falar de outras coisas alheias ao teatro. Este recurso é sempre acionado em vista de potencializar a crítica à monotonia da dramaturgia e aos autores ainda muito ligados às tradições obsoletas ou aos interesses econômicos. Assim, o fato de contornar os comentários das peças constitui, em si, uma crítica reprovativa ao que Gautier deveria apreciar. Já que não há nada de novo e de original, a função do folhetinista torna-se inválida, diante das inúmeras repetições de reprovações, o que autoriza Gautier a voltar-se a digressões teóricas sobre arte e a outros variados assuntos. Estes desvios estratégicos de Gautier dão lugar a assuntos periféricos como a necrologia de artistas, resenha de livros e ensaios de arte, o discurso interno sobre sua intensa atividade folhetinesca e, até mesmo, um suposto passeio. ${ }^{34}$ A publicação de 18 de dezembro de 1843 é um bom exemplo, pois, das 6 colunas que organizam normalmente o folhetim teatral à época, praticamente três delas são dedicas a uma inicial e longa digressão sobre um passeio do folhetinista em Paris, durante o qual visita o ateliê do artista Lechesne. Assim ele começa seu texto:

Vamos com frequência bem longe para ver coisas que não enxergaríamos se estivessem na rua onde moramos; uma viagem em Paris traria certamente descobertas e seria tão curiosa quanto aquela do capitão Ross ao polo Ártico $[\ldots]$.

Outro dia, levado por um não sei qual capricho de locomoção, saí de casa [...]. Audacioso, embrenhei-me corajosamente na rua Laval, uma rua fantástica, mas pouco frequentada [...] e ali, encontrei um monumento [...]; é claramente um ateliê de pintura [...]. ${ }^{35}$ (La Presse, 18 de dezembro de 1843).

\footnotetext{
${ }^{34} \mathrm{O}$ artigo de Patrick Berthier (2004) trata exatamente sobre esta "verve de contournement de Gautier" nos seus primeiros anos no La Presse.

35 "L'on va souvent bien loin pour voir des choses que l'on ne regarderait pas si eles étaient dans la rue où l'on demeure; un voyage à Paris amenerait bien des découvertes et serait autrement curieux que celui du capitaine Ross au pôle Arctique; [...]. L'autre jour, poussé par je ne sais quel capriche de locomotion, je sortis de chez moi [...]. Moi, plus audacieux, je m'engageai hardiment dans la rue Laval, une rue fantastique, aussi peu fréquentée [...] et là je trouvai un monument [...]; c'est bonnement un atelier de peintre [...]."
} 
E termina de contar o passeio lembrando-se de suas obrigações jornalístico-críticas: "Eis-nos bem longe do nosso assunto [...]; mas, acontece-nos tão raramente de ver alguma coisa que nos dê prazer que devem nos perdoar este desvio antes de chegar à nova ópera apresentada quinta passada no..."36 (La Presse, 18 de dezembro de 1843). Somente então, sem outros rodeios, passa à primeira das suas apreciações, no caso a ópera Il Fantasma, apresentada no Teatro Italiano: "Declaramos, pondo a mão na consciência, não ter entendido absolutamente nada da ação desta ópera." ${ }^{37}$ (La Presse, 18 de dezembro de 1843).

Outras vezes, uma única palavra basta para contornar o assunto teatral, como na crítica ao vaudeville apresentado no teatro Variétés, cujo título Jacquot, lembra ao folhetinista um célebre cão, personagem criado pelo também folhetinista Alfonse Karr, que é atormentado por um pássaro cacatua. Esta lembrança se desdobra em uma anedota fantástica sobre uma gata que "se encontrou na presença de um pequeno periquito verde", o qual ela acredita ser um frango. O folhetinista, narrador onisciente da história, contada em primeira pessoa, reproduz os pensamentos da gata e a conversa entre eles. O diálogo é disposto no jornal com as alíneas e com os caracteres gráficos de uma conversação, o que aponta, já pela estrutura gráfica, uma fissura na típica apresentação densa e contínua do artigo dentro da rubrica, bem como na página do jornal como um todo.

[...] a gata parou, retomou uma atitude meditativa, projetou sobre mim um olhar consultivo e formulou o seguinte axioma: "Os frangos não são verdes". $\mathrm{Eu}$ lhe respondi com um sinal de cabeça: "Você tem razão, judiciosa gata. Talvez seja um frango pintado? Continuou ela.

— Não sei, disse eu levantando os ombros com um ar de dúvida.

Vou ver, disse a gata entrelaçando-se à volta do periquito, as dez garras anteriores delicadamente lançadas para fora de sua bainha [...]. ${ }^{38}$ (La Presse, 23 outubro 1843)

\footnotetext{
36 "Nous voilà bien loin de nos affaires [...]; mais il nous arrive si rarement de voir quelque chose qui nous fasse plaisir qu'on doit nous pardonner ce détour avant d'arriver au nouvel opéra représenté jeudi passé sur le...".

37 "Nous déclarons, la main sur la conscience, n'avoir absolument rien compris à l'action de cet opéra.".

38“"...] la chatte s'arrêta, reprit une attitude méditative, me jeta un regard consultatif et formula cet axiome: 'Les poulets ne sont pas verts.'.
} 
Toda esta história constitui, por si só, um enorme desvio pleno de ironia considerando que ela está sendo contada num folhetim teatral. Primeiramente, porque a anedota não tem relação alguma com a peça comentada; em segundo lugar, visto que a revista teatral deveria, evidentemente, trazer uma apreciação dos méritos dos espetáculos, de modo que, a princípio, o folhetim não deveria se construir com base em uma ficção, oficialmente reservada ao romancefolhetim, tendo em vista o suporte; e, enfim, porque esta ficção causa uma dissonância interna à própria rubrica, assim como com o jornal, pois a elocução e o enunciado da digressão são materialmente tão bem construídos e posicionados no espaço do folhetim, que a pequena primeira coluna do bas de page, onde figura a historieta, atrai mais a atenção do leitor pelo aspecto mais arejado do que o longo e denso editorial, do alto da primeira página do jornal. Tal atitude literária do folhetinista contrasta, portanto, com a principal rubrica do jornal francês da época, o editorial, chamado então de premier-Paris, como uma manifestação da ironia jornalística, isto é, o uso de formas literárias que contrastam com o real e o factual da atualidade do periódico. No folhetim em questão, a destreza da escrita folhetinesca, de todo modo é, paradoxalmente, desvendada e reforçada na sequência, ao fim da anedota, em um parágrafo insigne, no qual a voz do escritor se superpõe à do jornalista.

Eis-nos bem longe da análise de Jacquot; porém, nossa história tem, por ela mesma, a desculpa de não ser nem trazida, nem motivada. Poderíamos muito bem alegar o nome de Jacquot como o fio desatado que o liga ao nosso folhetim; mas desprezamos semelhantes artifícios; e se como Grimm tínhamos vontade de contar histórias sobre explosivos, o faríamos sem dizer no meio da conversa: "Creio que acabei de escutar um tiro de fusil.". ${ }^{39}$ (La Presse, 23 outubro 1843)

Com o objetivo de explorar os usos e formas de escrita, a citação - explícita ou não era também um procedimento ligado à manifestação da ironia, sobretudo quando Gautierfolhetinista cita o Gautier-romancista, ocupando com a autorremissão quase quatro das cinco

\footnotetext{
39 “Nous voici bien loin de l'analyse de Jacquot; mais notre histoire a pour elle cette excuse de n'être ni amenée, ni motivée. Nous pourrions bien alléguer le nom de Jacquot comme le fil délié qui la rattache à notre feuilleton; mais nous méprisons de pareils artifices; et si comme Grimm nous avions envie de raconter des histoires sur le salpêtre, nous le ferions sans dire au milieu de la conversation: 'Je crois que je viens d'entendre un coup de fusil. '”.
} 
colunas da revista dedicada ao Théâtre de la Renaissance, e que recuperava tal qual parágrafos de reflexões presentes no capítulo XI do seu romance Mademoiselle de Maupin (1835).

No tempo em que passávamos os dias fazendo unirem-se duas rimas ao fim de uma ideia [...] escrevemos algumas páginas sobre o teatro tal como o entendíamos; - isso parecia muito simples, então. É verdade que não éramos folhetinista e que tínhamos por breviário um volume [...] de certo tipo chamado Shakespeare, o qual seria recusado hoje por todos os diretores como não tendo a ciência dos palcos [...].

Eis quais eram nossas ideias em 1835. - Confessamos, para o constrangimento de nossa razão, que hoje, 16 de dezembro de $1838,-[\ldots]$ temos ainda a mesma opinião.

- "O teatro com o qual sonhamos é um teatro singular." - Nele, vagalumes são lucernas [...]. ${ }^{40}$ (La Presse, 17 de dezembro de 1838)

A citação é indicada sutilmente ao leitor, porém não sinalizada graficamente pelas aspas nem pela menção ao título do romance, o que faz o leitor mais desatento - ou que não conhece a obra - talvez, ler a crítica como se fosse uma escrita original para o próprio rodapé. O trecho do folhetim “ "-O teatro com o qual sonhamos é um teatro singular.' ” é o início da transcrição emprestada do romance, contendo, esta primeira frase, certa adaptação em relação ao romance. ${ }^{40}$ Já a continuação do parágrafo, “- Nele, vagalumes são lucernas [...]”, não assinalada graficamente pelas aspas no jornal, já se trata do texto de Mademoiselle de Maupin, do qual serão reproduzidos dezesseis parágrafos sequenciais.

Novamente, parece que o escritor toma o lugar do folhetinista, aqui mais longamente, com o propósito de reavivar os princípios e valores do drama moderno, segundo seus conceitos, como forma de protestar contra o drama medíocre e a produção em série dos vaudevilles e das óperas-cômicas representadas, constantemente, nos principais teatros de Paris. A elaboração da escrita, entretanto, é astuta: o folhetinista toma emprestada a voz do narrador do romance - sua

\footnotetext{
40 "Au temps où nous passions les journées à faire se becqueter deux rimes au bout d'une idée [...] nous avons écrit quelques pages sur le théâtre tel que nous l'entendions; - cela paraissait tout simple alors ; il est vrai que nous n'étions pas feuilletoniste, et que nous avions pour bréviaire un volume [...] d'un certain drôle nommé Shakespeare, qui serait refusé aujourd'hui par tous les directeurs comme n'ayant pas la science des planches [...]. Voici donc quelles étaient nos idées en 1835. - Nous avouons, à la honte de notre raison, qu'aujourd'hui 16 décembre 1838, - [...] nous sommes encore du même avis.

-Le théâtre que nous rêvons est un singulier thèâtre.-Des vers luisants y tiennent lieu de quinquets [...].”.
} 


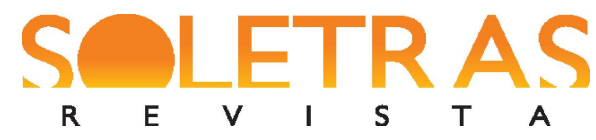

N. 40 - 2020.2 - PRISCILA RENATA GIMENEZ

própria personagem -, pela citação não marcada. O procedimento aponta para a intenção de assinalar seus princípios artísticos, ao invés de reafirmá-los com sua própria pena de folhetinista. Assim, seu posicionamento constrói-se pela ironia, pois é ferida a lógica da essência da crítica teatral, que deveria transmitir as atualidades dos espetáculos sem se concentrar em dogmas artísticos. Outra razão é porque esta ironia abala, igualmente, a lógica do processo de criação do romance, em virtude de o autor ferir toda a ficção da elaboração literária da narrativa ao assumir, como sendo do escritor, a voz criada e dada ao personagem narrador do romance, ou seja, ao identificar Gautier ao narrador. O último parágrafo da crítica é a retomada do folhetinista que conclui:

Quando abriram o teatro Renaissance tão brilhantemente por um discurso do Sr. Méry e um drama do Sr. Victor Hugo, cremos, por um instante, que nossas esperanças seriam realizadas. [...] porém, Lady Melvil, Olivier Basselin e os Parents de la fille nos desenganaram. [...] Na ausência de peças novas, por que não se representa neste teatro boas traduções de Shakespeare ou de Schiller, que formariam o gosto do público, desgastado pelas imundas rapsódias populares que o satura? ${ }^{41}$ (La Presse, 17 de dezembro de 1838)

Na escrita de Théophile Gautier folhetinista, outra forma de digressão de apelo surpreendente e, certamente, irônica, é encontrada no excerto abaixo em que a crítica é composta apenas de uma relação de atividades alternativas e dos bastidores - dos espetáculos e da produção dos folhetins pelos jornalistas - com as quais os folhetinistas se ocupariam durante a representação de certos espetáculos. O recurso é utilizado em críticas a dois teatros diferentes, como parte inicial do mesmo folhetim. A forma, o conteúdo e o tom irônico do folhetinista, no mínimo, apontam a intenção de provocar humor, quebrar o ritmo e o tom grave das rubricas acima do traço horizontal do folhetim. Naturalmente, o desvio também revela a inutilidade de

\footnotetext{
41 "Losqu'on ouvrit la Renaissance si brillamment, par un discours de M. Méry et un drame de M. Victor Hugo, nous crûmes un instant que nos esperances allaient être réalisées. [...] mais Lady Melvil, Olivier Basselin et les Parents de la fille nous eurent bientôt détrompé. [...] Pourquoi ne represente-t-on pas à ce théâtre, à défaut de pièces nouvelles, de bonnes traductions de Shakespeare ou de Schiller, qui formeraient le goût du public dérpavé par les immondes rapsodies [sic] dont on le sature?".
} 
comentar as referidas peças e o vazio (néant) ocasional na espera de representações que mereciam uma verdadeira crítica.

TEATRO DAS VARIÉTÉS. Deux Hommes noires, pelo Sr. ***

(Em benefício da mulher de uma antiga serpente jiboia, viúva com dezessete filhos na primeira infância.)

Durante esta apresentação, os folhetinistas passearam na passarela do Opéra, fumam seu charuto, jogam dominó ou deitaram-se às oito horas, mais ou menos solitariamente. - Os mais laboriosos formam o espírito e o coração pela leitura das Mémoires d'un poisson rouge, do Sr. Albéric Second.

TEATRO DO VAUDEVILLE

Foliquet, pelo Sr. X. (vaudeville dominical).

Enquanto este ato acontece, os críticos chegam penosamente à nona coluna de seu artigo semanal. A todo instante, o grupo de garotos vindos da tipografia do jornal sucedem-se em suas antessalas. ${ }^{42}$ (La Presse, 21 de fevereiro de 1843)

Por fim, a escrita heterogênea de Gautier se nutre também de outros escritores, estilos e formas de escrita resgatadas pela elaboração engenhosa do folhetinista, empregadas como um tipo de estudo de linguagens. Às vezes, estas experimentações aparecem como uma retomada de expressões de personagens do espetáculo comentado e tornam-se pequenas fórmulas de pastiche, como uma exclamação da protagonista transformada em versos alexandrinos: “" $O h$ ! Ce crime odieux ne s'accomplira pas !', s'écrie Mathilde" "43 (La Presse, 15 de agosto de 1843), fazendo uma alusão irônica, e consequentemente reprovativa às tragédias à moda clássica ainda produzidas nos teatros parisienses. Outras vezes, o crítico retoma trechos do texto dramático ou fragmentos de falas dos personagens, situando o leitor nos momentos do espetáculo que está

\footnotetext{
42 “THÉATRE DES VARIÉTÉS. Les Deux Hommes noires, par M. ***(Au bénéfice de la femme d'un ancien serpent boa, restée veuve avec dix-sept enfants en bas âge.) Pendant cette représentation, les feuilletonistes se promènent au passage de l'Opéra, fument leur cigare, jouent aux dominos ou se couchent à huit heures, plus ou moins solitairement. - Les plus laborieux se forment l'esprit et le cour par la lecture des Mémoires d'un poisson rouge de M. Albéric Second.". "THÉATRE DU VAUDEVILLE. Foliquet, par M. X. (vaudeville dominical). Tandis que cet acte se commet, les critiques arrivent difficulteusement à la neuvième colonne de leur article hebdomadaire. D'instant en instant, des députations de galopin partis de l'imprimerie du journal se succèdent dans leur antichambre.".

${ }^{43}$ Uma possível tradução seria “'Oh! Este crime odioso não se cumprirá’, exclama Mathilde”.
} 
sendo comentado. Por certo, a citação não é gratuita, pois indica, por exemplo, a intenção de fazer uma censura ao texto, ao estilo do dramaturgo, a tentativas mal sucedidas de dramas em versos clássicos, ou mesmo de reprovar a interpretação ou a entonação dos atores. Estas falas podem ser recriadas por meio da estratégia de mutação da escrita convencional, a fim de explorar o efeito irônico, cômico e humorístico da situação. O folhetim de 21 de agosto de 1837 apresenta um caso interessantíssimo, no qual Gautier recria a pronúncia exagerada e ridícula de dois atores em cena, por meio de uma escrita caricatural, elaborada por aliterações e com o ritmo das frases que reproduz a pronúncia dos atores:

É aqui que os atores Saint-Ernest e Delaistre produziram um efeito brilhante. Todo mudo sabe que em todos os melodramas reserva-se sempre uma cena de efeito para esses dois atores de fôlego. É um belo torneio de palavras; um faz soar todos os rr, o outro todos os ss. Há um momento em que a elocução tornase acalorada a ponto de não se entender nada mais que um ronco, de um lado, e um assobio, do outro. Todas as outras vogais e consoantes são totalmente suprimidas. Eis algumas frases da cena no momento em que se podia, ainda, distinguir as palavras: - "Você sabe, dizia Perkins, que não terria mais uma palavra a dizerrr parra te fazerr prrecipitarr morrro abaixo desta morrada? - E você, respondia Yorick, ssabe que sse eu te pegassse ssomente com essta mão aqui, você cairia no messmo insstante, pálido e glacial, ssobre estes pés que te essmagariam ssem piedade, inssensssato!....". ${ }^{4}$

\section{Considerações finais}

Valendo-se de sua habilidade de poeta, contista e romancista, Gautier folhetinista foi um jornalista notável ao produzir ao longo de décadas, principalmente, seu folhetim teatral. No rodapé dedicado aos espetáculos o escritor-jornalista endossa, na primeira década de sua

\footnotetext{
44 "C'est ici que les deux acteurs Saint-Ernest et Delaistre ont produit un effet brillant. Tout le monde sait que dans tous les mélodrames on réserve toujours une scène à effet pour ces deux acteurs à forte poitrine. C'est un beau tournoi de paroles; l'un fait sonner toutes les rr, l'autre toutes les ss; il arrive un moment où le débit s'échauffe au point qu'on n'entend plus qu'un ronflement d'un côté, et qu'un sifflement de l'autre, toutes les autres voyelles et consonnes sont absolument supprimées. Voici quelques phrases de la scène au moment où l'on pouvait encore distinguer les mots : - 'Sais-tu, disait Perkins, que je n'aurrais qu'un mot à dirre pourre te fairre prrécipiterre en bas de murres de cette demeurre? - Et toi, répondait Yorick, ssais-tu que ssi je te ssaisissais sseulement avec cette main que voici, tu tomberais à l'insstant, pâle et glacé ssouss ce genou qui te presserait sans merci, inssenssé !...'."
} 


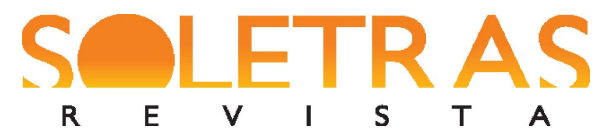

N. 40 - 2020.2 - PRISCILA RENATA GIMENEZ

atuação, a postura do romântico ironista, pela qual defende e mostra, pelos recursos da ironia, seus conceitos sobre a arte moderna, sobretudo, a arte dos palcos e a arte literária. Seu posicionamento sobre suas concepções artísticas é materializado pela poética aplicada na elaboração de seus folhetins, pela qual aprecia, contesta e sugere como deveriam se manifestar os espetáculos e o fazer literário, a partir daquele contexto de grandes transformações históricas, técnicas e sociais. Tal poética articula procedimentos literários, habilmente trabalhados, questionamentos do artista perante a realidade artística de seu tempo e sua própria condição de escritor-jornalista, edificados pela ironia literária. Criador de uma poética livre - dos paradigmas da crítica, bem como do jornalismo de atualidades - ele recria em sua própria escrita os contrastes entre o folhetim - espaço da arte, da ficção e da criação literária - e o próprio jornal, fundamental suporte e veículo da literatura ao longo do século XIX.

\section{Referências}

GIMENEZ, Priscila Renata. Uma visita a Madri no rodapé do jornal: Théophile Gautier e os relatos de um folhetinista viajante. Revista Nonada, v. 2, n. 23, p. 34-44, 2014.

. L'écriture littéraire des feuilletons musicaux: la poétique des contournements et de fictionnalisation chez Théophile Gautier et Hector Berlioz. In: Presse et opéra au XVIII ${ }^{\mathrm{e}}$ et XIX $^{\mathrm{e}}$ siècle. Média19, 2018. Disponível em: $<\mathrm{http}$ ://www.medias19.org/index.php?id=24208>. Acesso em: 30 mar. 2020.

BALZAC, Honoré. Les Journalistes. Monographie de la presse parisienne. In: KOCK, Paul. La Grande Ville. Nouveau tableau de Paris comique, critique et philosophique par Paul de Kock, Balzac, Dumas etc. Paris: Marescq, 1843-1844. 2 v., p. 129-208.

BARA, Olivier. Théophile Gautier, historien du théâtre?. Bulletin de la Société Théophile Gautier, Montpellier, n. 34, p. 46-60, 2012.

BELLATTI, Giovanna. Théophile Gautier journaliste à La Presse. Paris: Torino, Harmattan, 2008.

BERTHIER, Patrick. Théophile Gautier journaliste. De quelques pratiques d'écriture. In: THÉRENTY, Marie-Ève; VAILLANT, Alain (org.). Presse et plume. Journalisme et littérature du XIX'e siècle. Paris: Noueau Monde, 2004. p. 443-455.

BRUNET, François. Théophile Gautier et la musique. Paris: Honoré Champion, 2006. 
COURT-PEREZ, Françoise. Gautier, un romantique ironique: sur l'esprit de Gautier. Paris: Honoré Champion, 1998.

GAUTIER, Théophile. Mademoiselle de Maupin. Paris: Eugène Renduel, 1835-1836. 2 vol.

KALIFA, Dominique et al. (org.). La civilisation du journal: histoire culturelle et littéraire de la presse française au XIX ${ }^{\mathrm{e}}$ siècle. Paris: Nouveau Monde, 2011.

La Presse, 1837-1845. Disponível em:

$<$ https://gallica.bnf.fr/ark:/12148/cb34448033b/date.item>. Acesso em: 13 de abr. de 2020.

LAVAUD, Martine. Chiffres et colonnes: réflexions sur le morcellement de l'oeuvre de Gautier dans la presse de son temps. Bulletin de La Societé Théophile Gautier. «Le cothurne étroit du journalisme: Théophile Gautier et la contrainte médiatique ». Montpellier, n. 30, p. 19-40, 2008.

Théophile Gautier (1811-1872). In: KALIFA, Dominique et al. (org.). La civilisation du journal: histoire culturelle et littéraire de la presse française au $\mathrm{XIX}^{\mathrm{e}}$ siècle. Paris: Nouveau Monde, 2011. p. 1168-1184.

SOCIÉTÉ THÉOPHILE GAUTIER. Romans. Disponível em: $<\mathrm{http}: / /$ www.theophilegautier.fr/romans/>. Acesso em: 28 abr. de 2020

THÉRENTY, Marie-Ève; VAILLANT, Alain (org.). 1836 L'An I de l'ère médiatique. Paris: Noueau Monde, 2001.

\title{
Théophile Gautier, the feuilletonist fictionist-poet
}

\begin{abstract}
Théophile Gautier (1811-1872) was a poet, novelist, and short story writer, recognized in the pleiad of the 19th century, who also dedicated his life to journalism. His entire production for the periodic press constitutes relevant literary documents. This study is dedicated to an analysis of the writing of theatrical feuilletons written by Gautier for the Parisian newspaper La Presse in the 1840s. Based on the main studies about the relations between literature and press, in addition to critical studies about the writer-journalist, with the analyses and explanation of the first years of the author as a theatrical feuilletonist, we seek to demonstrate that his critiques to spectacles reveal artistic concepts, and that the aesthetic and composition of his fictionist and poetic pen from the Romantic era, articulated to a literary-journalistic writing, are inventive and transgressive against the typical speech of support. In the section of the feuilleton reserved for theatrical reviews, thanks to the liberty of the newspapers' footnotes, a space dedicated to literary transposition of reality, by language and by fiction, Théophile Gautier questions the panorama of the spectacles as well as day-to-day reality, narrating and appreciating the representations and the main dramatic and lyric plays of his time.
\end{abstract}

Keywords: Théophile Gautier. Theatrical feuilleton. La Presse. Literary writing. 
$\begin{array}{llllllll}\mathbf{R} & \mathbf{E} & \mathbf{V} & \mathbf{I} & \mathbf{S} & \mathbf{T} & \mathbf{A} & \mathrm{N} .40-2020.2-\text { PRISCILA RENATA GIMENEZ }\end{array}$

Recebido em: 30 de maio de 2020.

Aceito em: 15 de julho de 2020. 